\title{
Emulsion Liquid Membrane Extraction of Turquoise Blue Reactive Dye-Study on Membrane Breakage and Swelling
}

\author{
N. Othman ${ }^{1 *}$, S. N. Zailani ${ }^{2} \&$ N. Mili ${ }^{3}$ \\ ${ }_{1,2 \& 3}$ Department of Chemical Enginecring, Faculty of Chemical and Natural Resources Engineering, \\ Universitj Teknologi Malaysia, 81310 UTM Skudai, Johor, Malaysia
}

\begin{abstract}
Reactive dyes are the principal dyes used in batik industry in Malaysia. From the environmental point of view the dyes should be removed from wastewater because they are toxic in nature. Therefore, the removal and recovery of dyes from batik industry wastewater is absolute necessity in order to save raw materials and to protect environment. from hazardous compounds. An experiment was carried out using onulsion liquid membrane (ELM) process in batch system to study the extraction behaviour of Turquoise Blue which is commonly used in batik industry. Several parameters have been studied such as carricr and surfactant/emulsifier concentrations, stripping agent and extraction time. The liquid membrane was fotruulated using kerosene as diluent, SPAN 80 as emulsifier and tri-dodecylamine (TDA) as a carrier. Hydrodynamic condition to generate extraction process was at 1:3 treat ratio and $250 \mathrm{rpm}$ stirring speed for 10 minutes whilc the emulsification was clone at $12000 \mathrm{rpm}$ for 5 minutes using homogenizer. The result obtained shows that, more than $70 \%$ of Turquoise Blue was extracted at favourable condition of $0.07 \mathrm{M}$ TDA, $7 \%(\mathrm{w} / \mathrm{v})$ SPAN 80 and $0.5 \mathrm{M}$ Thiourea in $1 \mathrm{M} \mathrm{NaOH}$.
\end{abstract}

Keywords: Batik industry, emulsion liçuid membrane, extraction, reactive dyes, wastewater

\subsection{INTRODUCTION}

Disposal of synthetic dyes in the form of wastewater effluents poses severe hazards to the environment as these effluents contain large amount of surfactants, suspended solids, trace metals, color and have high chemical oxygen demand (COD) [1]. Textile wastewater is coloured effluent and the released of these wastes into receiving waters are contributed to the water pollution. Coloured effluents have been produced, most certainly, since the dyeing technique was invented. Dyes have an adverse aesthetic effect because they are visible pollutants which affect photosynthetic activity in aquatic life due to reduced light penetration [2]. Recently, more researchers had concerned on the treatment of dye wastewater as the environmental

\footnotetext{
*Coresponding to: N. Othman (email: norasikin@fkkksa. utm.my)
}

contamination by dye wastewater has becomes a great environmental problem [3]. The majority of synthetic dyes currently used are the highly water soluble azo-reactive dyes. Azo dyes are characterized by the existence of nitrogen-nitrogen double bonds $(-\mathrm{N}=\mathrm{N}-)$ and the bright color of their aqueous solutions. The azo-reactive dyes are used extensively in textile industries to their favourable characteristics of bright color, waterfast and simple application techniques with low energy consumption [4]. The main pollution source of textile wastewater as in batik industry comes from the dyeing processes.

Therefore, dyes colour is the most important environmental concern in the textile industrial wastewater since the colour must be removed from the wastewaters before discharge to any water body. Textile dyes are classified into three categories which are cationic, anionic and nonionic reactive dyes [5]. Cationic dye referred to 
one which is basic in reaction and unites with negatively charged ions of the material acted upon, anionic teferred to one which is acidic in reaction and unites with positively charged ions of the material acted upon such as Red 3BS, Turquoise Blue, Black B and Orange 3R. Non-ionic dye referred to one containing both reactive basic and reactive acidic groups and staining both acidic and basic elements. Due to toxicity level, cationic is the most toxic followed by anionic and nonionic dyes [5].

Reactive dyes with the benzidine and aromatic compound were found to potential carcinogenic amines have already been proved [6]. Turquoise Blue ( $\mathrm{T}^{\prime} \mathrm{B}$ ) as shown in Figure 1 is anionic reactive dye where sodium ion $\left(\mathrm{Na}^{+}\right)$which positive charge attached at dye compound contains benzidine and aromatic structure make it hazardous waste in batik industry effluents.

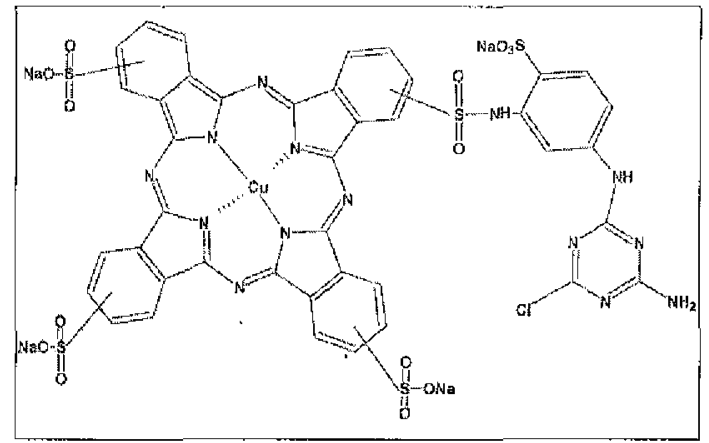

Figure 1 Chemical structure of turquoise blue dye

Various techniques have been found and investigate to remove dye stuffs from wastewater effluent. Adsorption of dye stuffs on cotton fabric wastewater using semi-activated carbon has been proposed by Ozoh [7]. The problem regarding to this method is disposal approach of the spent activated carbon after removing of dye stuffs. Removal and recovery of dyes using ion exchange were investigated by many researchers such as Naim and Yehia [8] and Farag et al. [9] on recovery of acid dyes from wastewater. Ahmad et al. [10] and Djenouhat et al. [11] were reported that membrane separation process offered the method for increasing the removal of dyes. However, fouling of membrane is the main problem for this technique. Solvent extraction or liquid-liquid extraction has been proposed by Panjit and Basu [12], Muthumaran and Palanivelu [13] and Muthumaran et al. [14] for both anionic and cationic dyes from wastewater.

Recently removals of dye stuffs have been employed rather than recovery process. Removal dyes from wastewater was concerned by environmental point of view due to colour and toxicity of dye compounds contribute pollution impact to water bodies. However, the purpose of recovery process will be more excellent than removal of dyes since the spent dyes will be reuse back using emulsion liquid membrane (ELM) technique. Emulsion liquid membrane is one of the promising techniques used in industrial separation process such as metals and chemicals removal from wastewaters. ELM is a heterogeneous mixture of two immiscible liquids. One of the liquid is dispersed in other phase to form globules or droplets in stable membrane (primary emulsion). The primary emulsion will be dispersed into external phase or phase to be treated to form double emulsion system. In this stage the extraction and stripping process occurred simultaneously in one step operation process.

This paper will present the membrane stability and efficiency of removal of TB anionic dye from simulated batik industry using ELM technique with tridodecylamine (TDA) as a mobile carrier [15]. The studies are carried out involving process parameters such as the carrier concentration, contact time, stripping agent concentration and agitation speed.

\subsection{EXPERIMENTAL PROCEDURES AND MATERIALS}

All the chemicals are used as received. Kerosene as diluents was obtained from Acros Organic, TDA as carrier and sodium hydroxide $(\mathrm{NaOH})$ as stripping agent from Merck Schuchardt $O H G$ Germany, thiourea (Tu) as additive or co-stripping agent from GCE Laboratory Chemicals and SPAN 80 from Fluka. Turquoise blue reactive dye was obtained from Batik Industry in Kuala Terengganu, Malaysia. The apparatus used are agitator IKA CMAG, homogeniser Heidolph Silent Crusher M and 1100 Series Spectrophotometer. 
TB dye solution was prepared by dissolving desired amount of dye concentration before each experiment. An equal volume of $5 \mathrm{ml}$ of organic solution and an aqueous strip solution will be stirred continuously at $12000 \mathrm{rpm}$ using homogeniser for 5 minutes to obtain a stable primary emulsion system. Then, the emulsion will be dispersed into external phase of $50 \mathrm{ppm}$ TB solution with treat ratio 1:3 (volume of emulsion: volume of external phase) to form the double emulsion (W/O/W) system for 10 minutes extraction at $250 \mathrm{rpm}$ agitation speed. The enulsion must be freshly prepared each time before dispersion experiments. After that the mixtuer was allowed for phase separation for 15 minutes. Then, the primary emulsion was separated from the aqueous treated wastewater and dye concentration in the aqueous was analysed.

The quantitative determination of reactive TB dye was made using a spectrophotometer at wavelength $\lambda=635 \mathrm{~nm}$. To determine dye mass balance for all phases, after separation of aqueous phase the external aqueous phase was analysed using this formula of percent removal efficiency, $\mathrm{R}$ :

$$
E=\frac{[D y e]_{i}-[D y e]_{f}}{[D y e]_{i}} \times 100 \%
$$

$$
D=\frac{[D y e]_{\text {org }}}{[D y e]_{a q}}
$$

Symbols:

$$
\begin{aligned}
{[\text { Dye }]_{i}=} & \text { Initial dye concentration } \\
{[\text { Dye }]_{f}=} & \text { Final dye concentration } \\
{[\text { Dye }]_{o r g}=} & \text { Concentration of dye in organic } \\
& \text { phase } \\
{[\text { Dye }]_{a q}=} & \begin{array}{l}
\text { Concentration of dye in organic } \\
\text { phase }
\end{array}
\end{aligned}
$$

The experimental setup for extraction for removal and recovery of TB reactive dye using ELM system is shown in Figure. 2. TB reactive dye is extracted into TDA-lkerosene under neutral condition and the extracted dye is stripped into 1 $\mathrm{MNaOH}$ with Tu. The reaction for extracting and stripping of the dye were represented by equation (I) and (II) in Figure 3. Equation (I) shows the mechanism of extraction between TDA in organic phase (org) and TB reactive dye to form the complex of dye and TDA. The mechanism of stripping process is shown in equation (II) using $\mathrm{NaOH}$ to strip the complex was formed.

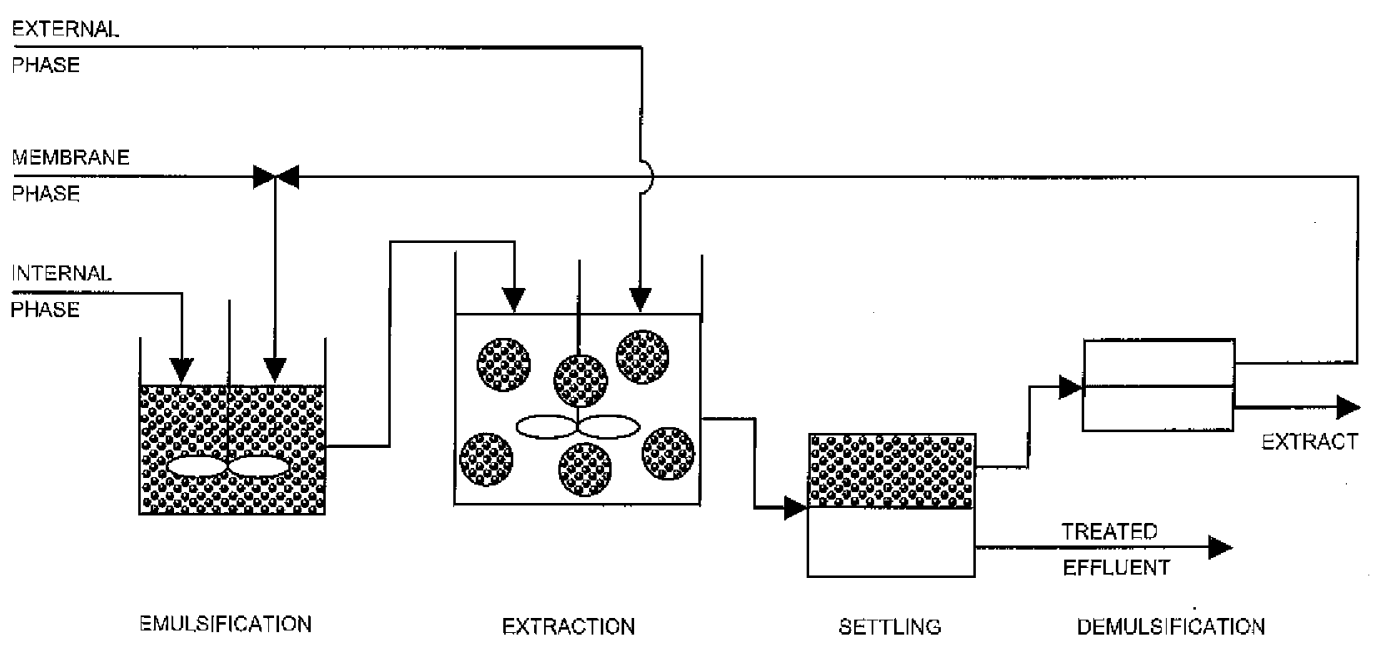

Figure 2 A schematic diagram of mixer-settler extraction using in emulsion liquid membrane 
Equation 3.1: Mechanism of reaction between TDA and dye ion in extraction process.

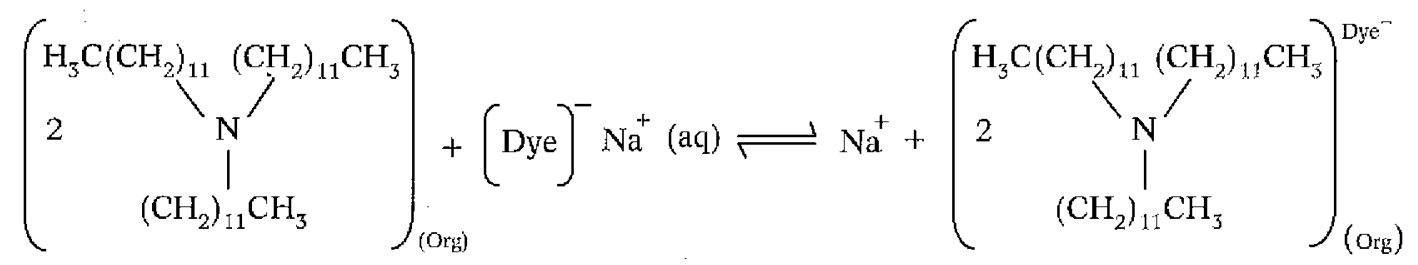

Equation 3.2: Mechanism of reaction between $\mathrm{NaOH}$ and dye ion in stripping process.

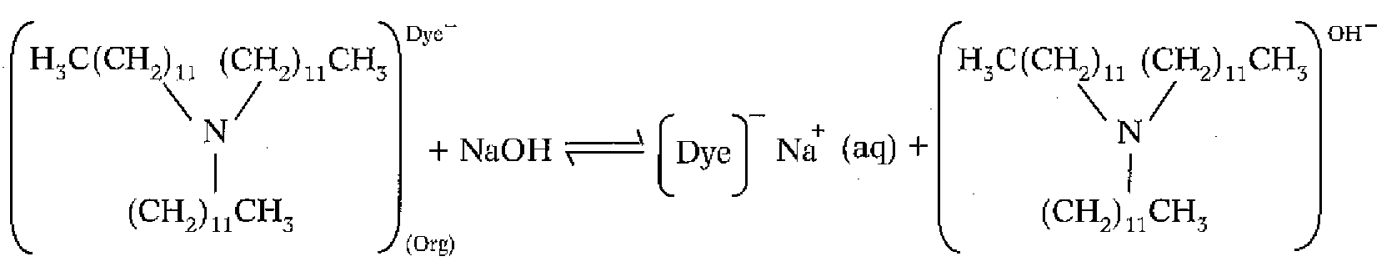

Figure 3 Reaction mechanism of extraction and stripping TB dye with TDA and NaOH

\subsection{RESULTS AND DISCUSSION}

\subsection{Effect of Carrier Concentration}

Figure 4 shows the effect of carrier concentration on the percentage of extraction and breakage. The concentration of carrier was varied from $0.01 \mathrm{M}$ to $0.1 \mathrm{M}$. Rate of facilitated transport of the solutes are directly affected by the amount of carrier that is presented in the liquid membrane [16]. Therefore the increase in carrier concentration will increase the ability of the membrane phase for extraction. As the concentration increased to 0.07 M, more dye solutes can be reacted with the carrier as they being transferred from external to internal phase.

However, at $0.1 \mathrm{M}$ of carrier concentration, the percentage of extraction decreases rapidly. This is due to the interfacial properties of the carrier resulting in increasing in viscosity of the membrane. There are also the factors of swelling as mentioned by Othman et al. [17]. At high concentration of carrier in the membrane phase, high osmotic swelling and membrane breakdown occurred. It means that the water in external phase will be transferred into internal phase and resulting to higher concentration in the external phase.

From Figure 4, it was observed that the extraction efficiency increased with the increase in the concentration of carrier from $0.01 \mathrm{M}$ to $0.07 \mathrm{M}$. Increase of TDA concentration accelerates the migration of the dye ions towards the oil phase interface towards an extraction process [18]. Further increase the amount of carrier higher than $0.07 \mathrm{M}$ decrease the degree of dye extraction. However, very high carrier contains in the membrane does not result in a benefit due to respective increase in viscosity, which leads to larger globules [11].

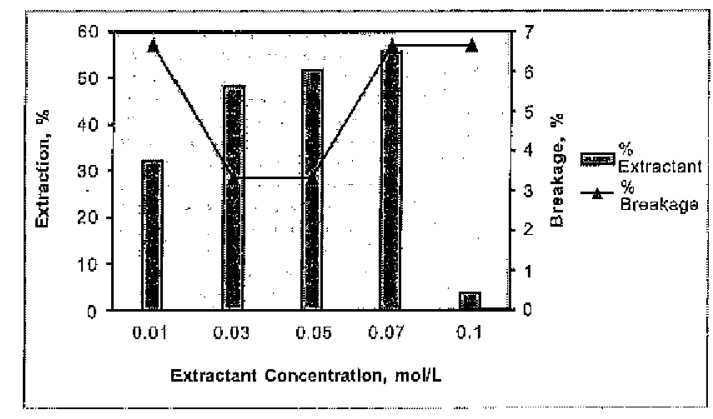

Figure 4 Percentage of extraction and breakage at the various carrier/extractant, Tridodecylamine (TDA) concentration [Span 80: 5\%, NaOH: $1 \mathrm{M}$, Thiourea: $0.5 \mathrm{M}$, agitation speed: $250 \mathrm{rpm}$, contact time: $10 \mathrm{~min}$, emulsifying speed: $12000 \mathrm{rpm}$, Initial concentration of dye: 50 ppm, treat ratio, 1:3] 


\subsection{Effect of Surfactant Concentration}

The surfactant concentration in membrane phase is most important to any ELM system. While it ensures the stability of membrane during the extraction, it also changes the viscosity of the membrane so as to change the mass transfer resistance [19]. The effect of this factor to the percentage of extraction and breakage are presented in Figure 5. The concentration of surfactant was varied from $1 \% \mathrm{w} / \mathrm{v}$ to $5 \% \mathrm{w} / \mathrm{v}$.

At $1 \% \mathrm{w} / \mathrm{v}$ and $3 \% \mathrm{w} / \mathrm{v}$ surfactant concentration, the percent of extraction is still considerably low. This is because low surfactant concentration destabilizes the membrane [19]. Therefore even the solutes transfer into the internal phase is actually increased; the amount of leakage due to membrane breakage also increases resulting to low net transport. As the surfactant concentration increased to $5 \% \mathrm{w} / \mathrm{v}$, the membrane becomes stronger. It was reported by Mortaheb et al. [20], higher concentration of surfactant will lower the surface tension of emulsion. This will lead to smaller globules and higher contact area between external phase and internal phase. This phenomenon also described by Othman et al. [17] where stability of the membrane increased due to an increasing adsorption of the surfactant in the interface by an increase in the interface film force of surfactant molecules.

However when the surfactant concentration continues to increase to $8 \% \mathrm{~W} / \mathrm{v}$, the extraction rate starts to decelerate. Although the emulsion was expected to be stabilized with increasing surfactant concentration [21], beyond the critical surfactant concentration the degree of stability becomes approximately constant due to the saturation of surfactants at the oil/water interface. But even though high degree of stability results in stronger membrane, it also leads to thicker globules wall. Therefore it cause higher mass transfer resistance and inversely decrease the removal efficiency. Mortaheb et al. [20] also described that excessive surfactant concentration lead to increase in swelling due to secondary emulsification of the entrained solvent by excess surfactant in primary emulsion.

The proportion of surfactant in organic phase is an important factor as it directly affects the stability, swelling, breaks up of ELM [20] and viscosity of ELM [21]. Figure 5 represents the variation of percentage extraction of $\mathrm{TB}$ and percentage swelling of membrane for various SPAN 80 concentrations.

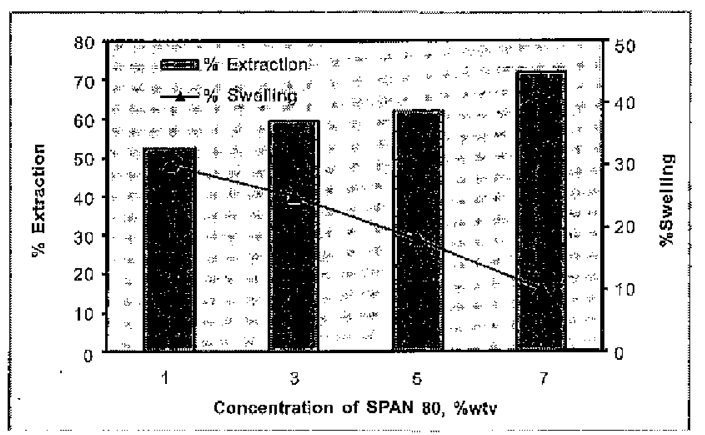

Figure 5 Variation of \% extraction of TB and \% swelling of membrane for different SPAN 80 concentrations uses $0.07 \mathrm{M}$ TDA concentration, $0.5 \mathrm{M} \mathrm{Tu}$ in $1 \mathrm{M}$ $\mathrm{NaOH}$ concentration, 5 minutes emulsifying time at $12000 \mathrm{rpm}$ and 10 minutes extraction time at $250 \mathrm{rpm}$

The results presented in Figure 5 show that an increase in the concentration of SPAN 80 increased the stability of emulsion. At lower SPAN 80 concentration (less than $5 \% \mathrm{w} / \mathrm{v}$ ), emulsion break easily leading to poor extraction of $\mathrm{TB}$ because the less emulsion interfacial surface areas between internal phase and membrane phase plus less dispersion interfacial surface areas between external continuous phase (dye solution) and membrane phase [22].

These findings also indicate that the percentage swelling of membrane was very obvious even the SPAN 80 concentration was increased to $7 \mathrm{w} / \mathrm{v} \%$. It is because SPAN 80 which molecular weight $428.61 \mathrm{~g} / \mathrm{mol}$ has a large hydrophilic group mainly

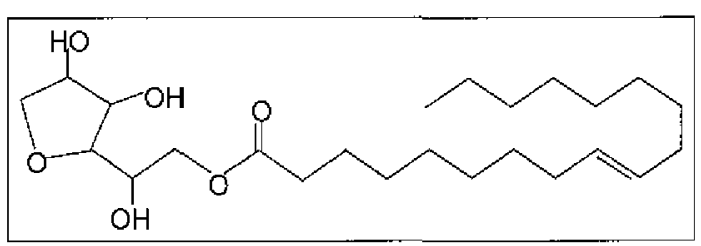

Figure 6 Chemical structure of SPAN 80 
composed of oxygen with high electronegativity thus may have the highest hydration capacity and largest diffusivity [23]. Figure 6 shows the chemical structure of SPAN 80.

\subsection{Effect of Stripping Agent Concentration}

The effect of Tu concentration in $\mathrm{NaOH}$ in the internal phase on both extraction of TB and swelling of membrane is shown in Figure 7. Different Tu concentration ranging from $0.1 \mathrm{M}-$ $0.7 \mathrm{M}$ were used. It is observed that the maximum extraction (71.74\%) occur at Tu concentration of $0.5 \mathrm{M}$. The extraction of dye increases with increasing the Tu concentration from $0.1 \mathrm{M}-0.5$ M. This may be due to the increase in the capacity of the internal phase by increase its concentration, which delay the accumulation of the carrier complex in the peripheral oil layer [24]. Further increase of Tu concentration up to $0.7 \mathrm{M}$ cause decreased the extraction rate since the excess $\mathrm{Tu}$ causes swelling of emulsion leading to destabilization of liquid membrane system causing reducing in percentage extraction. At lower concentration (below $0.5 \mathrm{M}$ ) of 'Tu, in $\mathrm{NaOH}$, almost of reactant is consumed in the internal phase resulting in lower efficiency [25]. Based on the result has shown, the optimum Tu concentration in $\mathrm{NaOH}$ as stripping agent is found to be $0.5 \mathrm{M}$.

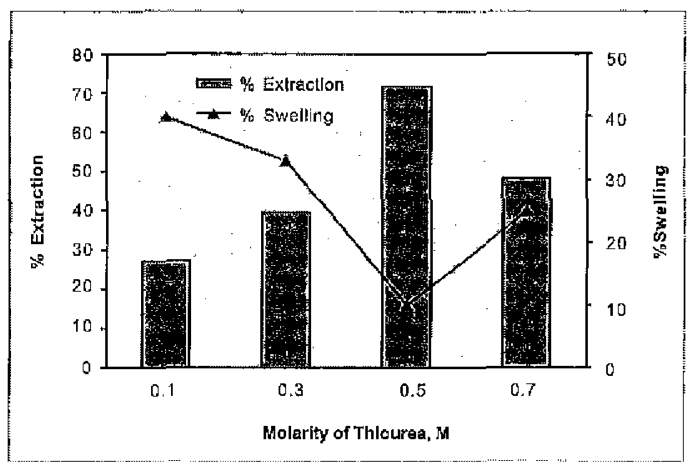

Figure 7 Variation of \% extraction of TB and \% swelling of membrane for different Tu concentrations using $0.07 \mathrm{M}$ TDA concentration, $1 \mathrm{M} \mathrm{NaOH}$ concentration, $7 \mathrm{w} / \mathrm{v} \%$ SPAN 80,5 minutes emulsifying time at $12000 \mathrm{rpm}$ and 10 minutes extraction time at $250 \mathrm{rpm}$

\subsection{Effect of Stirring Speed}

The effect of agitation speed during extraction on percentage of extraction and brealsage is shown in Figure 8 . The agitation speed was varied at 150 rpm to $450 \mathrm{rpm}$. At $150 \mathrm{rpm}$, it was observed that most emulsion globules are not properly dispersed in the external phase due to the low agitation speed. The emulsion only spread at certain part of the external phase and mostly at the water surface resulting in low percentage of extraction.

As the agitation speed increased to $250 \mathrm{rpm}$, the emulsions started to disperse uniformly and the globules will become smaller due to the fluid shear. There will be large surface area for mass transfer of solutes to the internal phase. The increases in agitation speed also reduce the thickness of boundary layer at interface of emulsion globules and internal phase. Both of these factors lead to higher percentage of extraction since there are more chances on mass transfer. However at $350 \mathrm{rpm}$ and $450 \mathrm{rpm}$, percent of extraction clecrease. This observation indicates that dye concentration in external phase increased back after the minimum concentration was reached. This increase in concentrations during later phase of extraction resulted due to emulsion rupture by fluid shear is greater than the rate of extraction. This was also described by Mok et al. [26] as

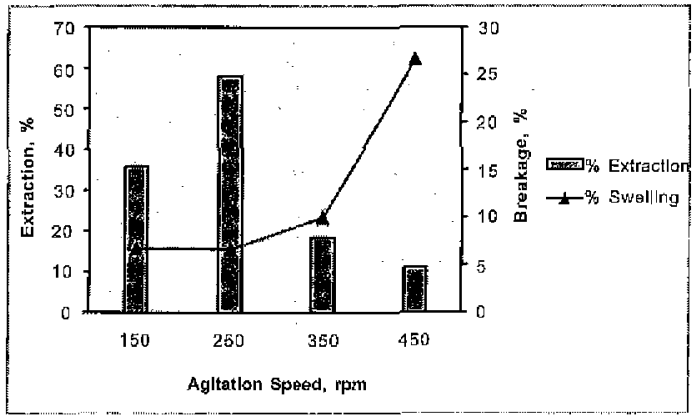

Figure 8 Percentage of extraction and breakage at the various agitation speeds during extraction [TDA: $0.07 \mathrm{M}$, Span $80: 5 \%$, $\mathrm{NaOH}: 1 \mathrm{M}$, Thiourea: $0.5 \mathrm{M}$, contact time: $10 \mathrm{~min}$, emulsifying speed: 12000 $\mathrm{rpm}$, Initial concentration of dye: 50 ppm, treat ration: 1:3] 
agitation speed increasing, membrane breakage will increase due to fluid shear and feed phase entrainment. Instability of emulsion due to fluid shear is also mentioned by Park et al. [27].

The effect of agitation speed on both extraction of TB and swelling of membrane is shown in Figure 8. The optimum stirring speed was at $250 \mathrm{rpm}$ because gives the maximum extraction of TB and minimum swelling of membrane. At high agitation rate hydrodynamic shear and swelling work together causing lower extraction [17]. Increasing the stirring speed above $250 \mathrm{rpm}$ not only decreases the extraction efficiency but also affects the stability of membrane.

For lower stirring speed (below $250 \mathrm{rpm}$ ), the extraction efficiency decrease because of formation of larger emulsion globules hindrance for the mass transfer. Higher stirring speed and larger mass transfer area bring faster mass transfer rate, and vice versa [18]. Unfortunately, too fast speed will result the membrane break easily and lower the extraction percentage of TB as well.

\subsection{CONCLUSIONS}

All the parameters studied such as concentration of $\mathrm{Tu}$ in $\mathrm{NaOH}$, concentration of SPAN 80 , concentration of carrier and agitation speed were affected the percentage of extraction of $\mathrm{TB}$ reactive dye and swelling of membrane. The maximum percentage of extraction of TB was found to be higher than $70 \%$ at the optimum working conditions of $0.07 \mathrm{MTDA}, 0.05 \mathrm{MTu}$ in $1 \mathrm{MNaOH}$, $250 \mathrm{rpm}$ agitation speed for 10 minutes, $7 \mathrm{w} / \mathrm{v} \%$ SPAN 80 and $12000 \mathrm{rpm}$ emulsifying speed for 5 minutes. The ELM technique was shown to be of interest for the treatment of $\mathrm{TB}$ reactive dye from simulated batik industry wastewater.

\section{ACKNOWLEDGMENTS}

The authors would like to acknowledge the financial support from the Ministry of Science Technology and Innovation (MOSTI), Malaysia (Vote No. 79336) and the Universiti Teknologi Malaysia for make this study possible.

\section{REFERENCES}

[1] Kim, T. H., C. Park, J. Yang, and S. Kim. 2004. Comparison of Disperse and Reactive Dye Removals by Chemical Coagulation and Fenton Oxidation. J. Hazard. Mater. B112: 95-103.

[2] Jusoh, A., Y. K. Tam, A. G. Liew, M. J. Megat, and K. Saed. 2004. Adsorption of Remazol Dye onto Granular Activated Carbon in Fixed Bed: A Case Study of Red 3BS. J. Engr. and Technol. 1: 58-63.

[3] Shin, S. H., Y. H. Kim, S. K. Jung, K. H. Suh, S. G. Kang, S. K. Jeong and H. G. Kim, 2004. Combined Performance of ElectroCoagulation and Magnetic Separation Processes for Treatment of Dye Wastewater Korean J. Chem. Eng. 21: 806-810.

[4] Asouhidou, D. D., K. S. Triantafyllidis, N. K. Lazaridis, K. A. Matis, S. S. Kim, J. Thomas and T. J. Pinnavaia. 2009. Sorption of Reactive Dyes from Aqueous Solutions by Ordered Hexagonal and Disordered Mesoporous Carbons. J. Microporous and Mesoporous Mater. 117: 257-267.

[5] Mishra and M. Tripathy G. 1993. A Critical Review of the Treatment for Decolorization of the Textile Effluent.

[6] Harbhajan Singh. 2006. Mycoremediation: Fungal Bioremediation. New Jersey: John Wiley \& Sons, Inc, Publication Hobolken.

[7] Ozoh PTE. 1997. Adsorption of Cotton Fabric Dyestuffs Wastewater on Nigeria Argicultural Semi Activated Carbon. Env. Monit Assess. 46: 255-265.

[8] Naim Mona M and El Abd Yehia M. 2002. Removal and Recovery of Dyestuffs from Dyeing Wastewater. Separation Purification Methods. 31: 171-228.

[9] Farag, S., M. H. Abo - Shosha, and N. A. Ibrahim. 1994. Removal of Various Acid Dyes by means of an Amido/Methylene Diacrylamide/Dimethyl Amino Ethyl Methacrylate Anion Exchange Compound. Tinctoria. 91: 48-51.

[10] Abdul Latif Ahmad, Wan Azlina Harris, Syafie and Ooi Boon Seng. 2002. Removal of Dye from Wastewater of Textile Industry 
using Membrane Technology. Jurnal Teknologi. 36(F): 31-44.

[11] Djenouhat, M., O. Hamdaoui, M. Chiha, and Mohamed H. Samar. 2008. Ultrasonicated Assisted Preparation of Water-in-Oil Emulsions and Application to the Removal of Cationic Dyes from water by Emulsion Liquid Membrane Part 2. Permeation and Stripping. Separation and Purification Technology. 63: 231-238.

[12] Pandit, P. and S. J. Basu. 2002. Removal of Organic Dyes from Water by Liquid-liquid Extraction using Reverse Micelles. Colloid Interface Science. 245: 208-214.

[13] Muthumaran, G. and K. Palanivelu. 2004. Selective Extraction and Separation of Textile Anionic Dyes from Aqueous Solution by Tetratbutyl Ammonium Bromide. Dyes and Pigments. 64: 251-257.

[14] Muthumaran G., Tjoon Tow Teng, Cheu Peng Leh and I. Norli. 2009. Extraction and Recovery of Methylene Blue from Industrial Wastewater using Benzoic Acid as an Extractant. Journal of Hazardous Materials. 163: 363-369.

[15] Othman N., N. Mili, A. Idris, and S. N. Zailani. 2009. Liquid Membrane Formulation for Removal of Dyes from Liquid Waste Solution Using Emulsion Liquid Membrane Process. Membrane of Science and Technology Conference Kuala Lumpur.

[16] Kaghazchia, T., A. Kargaria, R. Yegania, and A. Zareb. 2006. Emulsion Liquid Membrane Pertraction of L-lysine from Dilute Aqueous Solvtions by D2EHPA Mobile Carrier. Desalination. 190: 161-171.

[17] Othman, N., C. K. Hie, M. Goto, and H. Mat. 2005. Emulsion Liquid Membrane Extraction of Silver from Photographic Waste Using Cyanex 302 As A Mobile Carrier. Journal Solvent Extraction and Rsearch Development Japan. 13: 191.

[18] Pan Lu Ting. 2006. Extraction of Amino-J Acid from Waste-water by Emulsion Liquid Membrane. Chinese Journal of Process Engineering. 6: 738-741.
[19] Shen, J. Q., W. P. Yin, Y. Z. Zhao, and L. J. Yu. 1996. Extraction of Aniline using Emulsion Liquid Membranes Featuring a Cationic Carrier. Journal of Membrane Science. 120 : 45-33.

[20] Mortaheb, H. R., M. H. Amini, F. Sadeghian, B. Mokhtarani, and H. Daneshyar. 2008. Study on a New Surfactant for Removal of Phenol from Wastewater by Emulsion Liquid Membrane. Journal of Hazardous Materials. 160: $582-588$.

[21] Chiha, M., M. H. Samar, and O. Hamdaoui. 2006. Extraction of Chromium (VI) from Sulphuric Acid Aqueous Solutions by a Liquid Surfactant Membrane (LSM). Desalination. 194: 69-80.

[22] Miesiac I., K. Schugerl and J. Szymanowski. 1992. Emulsion Stability and Potassium Leakage in Emulsion Liquid Membrane Systems. Journal of Radioanalytical and Nuclear Chemistry. 163(1): 181-191.

[23] Yinhua Wan and Xiujuan Zhang. 2002. Swelling Determination of W/O/W Emulsion Liquid Membranes. Journal of Membrane Science. 196: 185-201.

[24] Hasan M. A., R. F. Aglan and S. A. El-Reefy. 2009. Modelling of Gadolinium Recovery from Nitrate Medium with 8-hydroxyquinoline by Emulsion Liquid Membrane. Journal of HazardousMaterials. 166: 10761081.

[25] Chandan, D., M. Rungta, G. Arya, S. Dasgupta, and Sirshendu De. 2008. Removal of Dyes and Their Mixtures from Aqueous Solution Using Liquid Emulsion Membrane. Journal of Hazardous Metarials. 159: 365371.

[26] Mok, Y. S., S. C. Lee, and W. K. Lee. 1995. Synergistic Effect of Surfactant on Transport Rate of Organic Acid in Liquid Emulsion Membranes. Separation Science Technology. 30(3): 399-417.

[27] Park, Y., A. H. P. Skelland, J. Larry, Forney, and J. H. Kim. 2006. Removal of Phenol and Substituted Phenols by Newly Developed Emulsion Liquid Membrane Process. Water Research. 40: 1763-1772. 